\title{
Larsen Syndrome in a Newborn
}

\author{
BS NAHER
}

\begin{abstract}
Summary:
Larsen syndrome, a congenital genetic disorder of collagen formation, is reported in a female newborn. The affected newborn has presented with dish like facies, multiple joint dislocations, gross hypotonia, cleft palate, spatulated thumb
\end{abstract}

\section{Introduction:}

Larsen syndrome is a congenital disorder of collagen formation that leads to multiple joint dislocations, abnormal facies, spine abnormalities and neck instability ${ }^{1}$.This is a complex disorder with genetic heterogeneity, and with both autosomal dominant and autosomal recessive patterns of inheritance. Mutations in gene encoding filamin B (FLNB) result in Larsen syndrome. This gene has an important role in vertebral segmentation, joint formation and endochondral ossification. The first description of the disorder later known as Larsen syndrome was given by Kaijser in $1935^{2}$. He reported a case with multiple congenital malformations including knee dislocation and facial deformities with family history of congenital deformities of musculoskeletal system. In 1950, Larsen reported six unrelated patients with multiple joint dislocation associated with facial abnormalities. The most striking findings were typical flattened "dish like” facies with depressed nasal bridge, mid face hypoplasia and widespaced eyes. The joints most often affected were the knees, elbows and hips. Abnormalities of the foot, hand, spine including cleft palate were also found. Latta ${ }^{3}$ reported malformation of the larynx gives respiratory distress. He also identified a juxtacalcaneal accessory bone that may be specific for the syndrome.In the prenatal diagnosis of Larsen syndrome ultrasonography has got potential role. Multiple joint dislocations resulting in abnormal position of the legs and knees are the main sonographic features that establish the diagnosis.In addition, demonstration of a depressed nasal bridge, hypertelorism, a prominent forehead and club feet also support the diagnosis as these are the characteristic features of Larsen syndrome. Moreover postnatal physical findings and radiologic examination enable one to make a definite diagnosis based on multiple joint dislocations, short metacarpal with multiple ossification centers and abnormal vertebral segmentation in the upper thoracic and cervical regions.

Address of Correspondence: Dr. Begum Sharifun Naher, Associate Professor of Neonatology, Sir Salimullah medical College and Mitford Hospital, Dhaka

Received: 9 January, 2014

Accepted: 1 December, 2014 and fingers. Diagnosis is made on the basis of positive family history, remarkable clinical features and characteristics radiological findings. This rare syndrome is the first case report so far in Bangladesh.

(J Banagladesh Coll Phys Surg 2015; 33: 52-54)

Most authors have found a familial occurrence of the syndrome. Habermann ${ }^{4}$ reported four cases of Larsen syndrome in three generations of one family and suggested a dominant mode of inheritance. We are reporting this case as this disorder may remain unrecognized or diagnosed as other disorder of short stature like Achondroplasia because of its rarity. So far our knowledge is concerned this is the first case report in newborn in Bangladesh.

\section{Case Report:}

Baby of Moyna, a 3 hour old female neonate was admitted to neonatal care unit of Mitford hospital with the complaints of short lower limbs. The baby was born in this hospital at 39 weeks of gestation by lower uterine cesarean section due to breech presentation and fetal distress. Mother never received any antenatal check up during her pregnancy. Baby cried immediately after birth and umbilical cord was cut aseptically. According to the family history one of her paternal aunt, 23 years of age was of short stature. Her height was 3.5 feet with short lower limbs but she was intelligent. On query she informed us about her health. She said she was under care of an orthopedic surgeon for congenital dislocation of both knee and hip joints and osteoarthritis.

On examination, face of the baby was dysmorphic with depressed nasal bridge, hairy scalp and forehead. There was midfacial hypoplasia (Fig-1). A small cleft palate

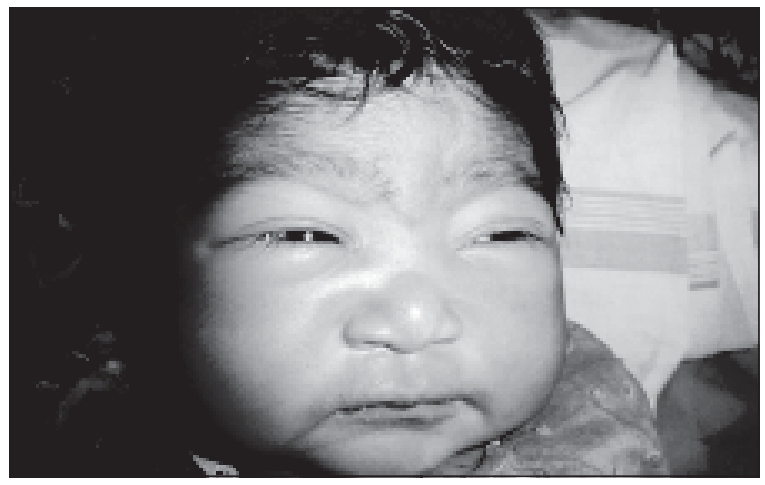

Fig.-1: Flat dish like facies with depressed nasal bridge and hypertelorism and hairy forehead 
was present involving the soft palate only. Her respiratory rate was $76 / \mathrm{min}$. Heart rate was $154 / \mathrm{min}$. Length was $45 \mathrm{~cm}$ and birth weight was 2800 gram. Air entry was good, heart sound was normal with no murmur on auscultation. Umbilicus was healthy and no organomegally was found. Both knee joints were hyper mobile and extension was possible up to 90 degree (Fig-2). Muscle tone was diminished but tendon reflexes were normal. There was spatulated thumb and other fingers (Fig-3). So on the basis of clinical features she was diagnosed as early onset neonatal sepsis with Larsen syndrome. On investigation, haematological reports were normal but radiological survey of whole body showed posterior dislocation in both hip joints including dislocations in all other big and smaller joints of lower limbs (Fig-4). She received the empirical treatment of neonatal sepsis. After consultation with orthopedic department manual stretching exercise was started and finally she was discharged for coming for follow up visit in the out patient department of orthopedics after three months. According to them surgical replacement of hip and knee joints may be helpful in future for this patient.



Fig.-2: Hypermobile knee joints with hypotonia

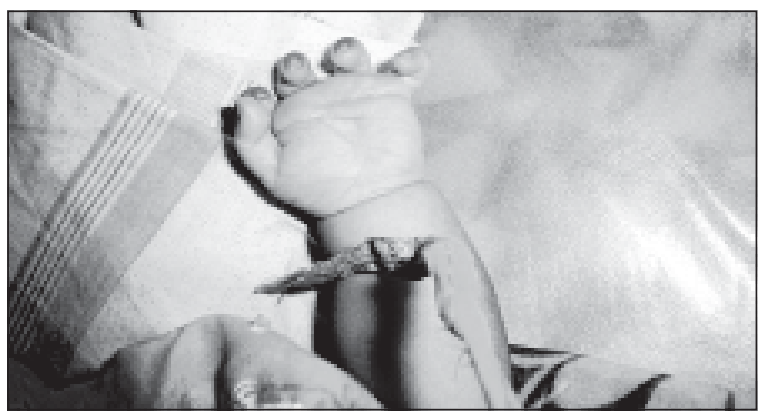

Fig.-3: Spatulated thumbs and other fingers

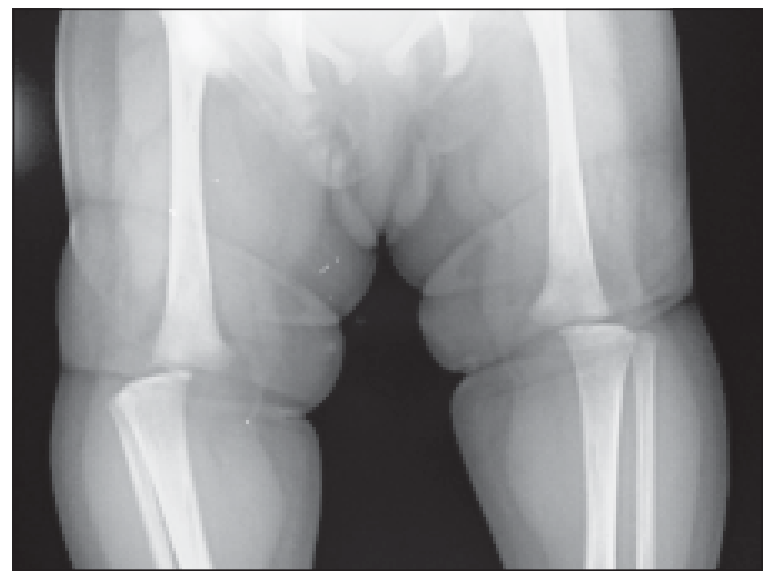

Fig.-4: Radiological image of knee joints showing bilateral dislocation.

\section{Discussion:}

Larsen syndrome is a rare inherited defect of connective tissue formation that is transmitted in an autosomal dominant and recessive pattern. First described by Larsen in 1950.Its defining features consist of multiple congenital joint dislocation usually of the hips, knees and elbows, frontal bossing, a depressed nasal bridge, hypertelorism, a flat face, distinctive deformities of hand and calcaneus may lead to major spinal instability and spinal cord injury ${ }^{5}$ , 6. In Table-I, all abnormalities ever described in cases supposed to have this disorder are listed.

\section{Table-I}

\section{Abnormalities described in patients with} Larsen syndrome ${ }^{7}$

A. Abnormalities affecting the musculoskeletal system General : Muscular hypotonia

Head: Prominent forehead with depressed nasal bridge and widespaced eyes.

Vertebral column and rib cage: Spina bifida. Pectus carinatum/ excavatum

Upper extremity: Dislocated elbow. Spatulated thumbs.Short metacarpals

Lower extremity: Dislocated hip joints.Dislocated knees

B. Other manifestations:

Mental development: Retarded in a few patients

Central nervous system: Gliosis in the cervical medulla

Respiratory tract/ oral cavity: Maldeveloped laryngeal castilage. Cleft palate/uvula

Genito urinary tract: Undescended testes. 
Our case has added short stature with short limbs and excessively hairy scalp with low posterior hair line.

A female newborn having physical findings consistent with Larsen syndrome is presented here. Her paternal aunt, 23 year old is apparently short with short lower limbs. On query she told us that she is also having treatment for joint pain for long time. We searched her prescription and found that she has bilateral congenital dislocation of both hip and knee joints. She is under the care of an orthopedic surgeon and has been suffering from osteoarthritis, a complication of Larsen syndrome. This family history could point to a dominant mode of inheritance.

We consulted with the department of orthopedics the surgeon advised stretching exercise of both knee joints for three weeks and recommended for surgical hip replacement later. Most authors advocate operative treatment ${ }^{8}$. Although the ultrasonography has the key role in the prenatal diagnosis as mother did not receive antenatal care it was never possible to know the sonographic features in this case. Histopathological examination was also not done as parents did not allow us for this kind of invasive procedure.So the postnatal physical findings like mid face hypoplasia, cleft soft palate, hypotonia, hyperextension of knee, multiple joint dislocation like hip, knee and other small joints of lower extremities and radiological examination enabled us to make a definitive diagnosis of Larsen syndrome.

The prognosis can be relatively good after aggressive orthopedic management although some cases are lethal. Many patients begin walking late. Osteoarthritis involving large joints and progressive kyphoscoliosis are potential complications. Airway obstruction due to tracheomalacia and bronchomalacia may be life threatening. Prenatal diagnosis is essential for proper management, either by termination of pregnancy when diagnosis is done very early or by preparation for anticipated perinatal complication when diagnosis is late. There is potential role of ultrasonography in the prenatal diagnosis of Larsen syndrome ${ }^{9}$. In this case mother did not seek for a neonatal care during her pregnancy. So there was no scope for prenatal diagnosis.

Conclusion: Any newborn with short stature and gross hypotonia and hypermobile joints must have radiological examination so that Larsen syndrome can't be missed in our clinical practice and proper counseling for the risk of recurrence may be performed to the family.

\section{References:}

1. Larsen LJ, Schottstaedt ER, Bost FC: Multiple congenital dislocations associated with characteristic facial abnormality. J Pediatr1950; 37: 574.

2. Kaijser, R. Uber kongenitale Kniegelenksluxationen. Acta orthop scand. 1935; 6: 1-20.

3. Latta R.J, Graham C B, Aase J, Scham S M, Smith D W. Larsen syndrome: A skeletal dysplasia with multiple joint dislocations and unusual facies. J Pediat. 1971; 78: 291-98.

4. Habermann E T, Sterling A, Dennis R I. Larsen syndrome: A heritable disorder.J Bone JT Surg. 1976; 58: 558-61.

5. Al Kaissi A, Altenhuber J, Grill F, Klaushofer K. Significant traumatic atrophy of the spinal cord in connection with severe cervical vertebral body hypoplasia in a boy with Larsen syndrome: a case report and review of the literature. Cases J. 2009; 17: (2) 6729.

6. Bowen JR, Ortega K, Ray S, Mac Ewen GD. Spinal deformities in Larsen syndrome. Clin Orthop. 1985; 197: 159-63.

7. Ronningen H, Bjerkreim I. Larsen syndrome. Acta orthop scand. 1978; 49: 138-42.

8. Curtis BH, Fisher RL. Heritable congenital tibiofemoral subluxation. Clinical features and surgical treatment. J Bone JT Surg. 1970; 52: 1104-14.

9. Lewit N, Batino S, Groisman GM: Early prenatal diagnosis of Larsen syndrome by transvaginal sonography. J Ultrasound Med 1995; 14: 627. 